Isabel A P Walsh

Jorge Oishi

Helenice J C Gil Coury

\section{Clinical and functional aspects of work-related musculoskeletal disorders among active workers}

\section{Aspectos clínicos e funcionais de distúrbios músculo-esqueletais entre trabalhadores ativos}

\begin{abstract}
OBJECTIVE: To evaluate musculoskeletal disorders among active industrial workers.

METHODS: The study was carried out in São Carlos, Southeastern Brazil, in 2005. One hundred and thirty-four female workers were physically evaluated and answered questions about their physical symptoms, filled out a pain scale and gave responses in the Oswestry Disability Questionnaire, and the Work Ability Index questionnaire. The data were analyzed descriptively, and in correlation tests and through applying logistic regression. The outcome was evaluated in relation to the perceptions of pain, symptoms, physical assessment, ability to work and disability.
\end{abstract}

RESULTS: Clinical evaluations and sick leave presented positive correlations with the subjective variables. The Work Ability Index presented a negative correlation with the physical disability index $(\mathrm{r}=-0.69)$. Symptoms reported at the time of the assessment presented a good correlation with the results from the pain scale and the clinical findings. Previous sick leave showed an association with disability (OR=1.13; 95\% CI:1.08;1.18).

CONCLUSION: Symptom reports and pain scales may be useful for assessing current conditions at the time of evaluating individuals with work-related musculoskeletal disorders, as they are easier to apply. In more severe cases of such injuries, clinical and functional evaluations and questionnaires such as those relating to ability to work and disability are preferable. Precise and specific evaluations of these disorders may contribute towards fairer legal and administrative decisions.

KEY WORDS: Occupational health. Cumulative trauma disorders. Occupational risks. Work capacity evaluation.
Programa de Pós-graduação em Fisioterapia. Universidade Federal de São Carlos. São Carlos, SP, Brasil

Correspondence:

Isabel A. P. Walsh

R. Comendador Gentil de Azevedo, 84

13575-600 São Carlos, SP Brasil

E-mail: ewalsh@terra.com.br 


\section{RESUMO}

OBJETIVO: Avaliar os distúrbios osteomusculares entre trabalhadores ativos da indústria.

MÉTODOS: O estudo foi realizado em São Carlos, SP, em 2005. Cento e trinta e quatro trabalhadoras foram fisicamente avaliadas e responderam a questões sobre sintomas físicos, escala de dor e aos questionários: de Incapacidade Oswestry e o Índice de Capacidade para o Trabalho. Os dados foram analisados descritivamente, em testes de correlação e regressões foram aplicados. O desfecho foi avaliado em relação à percepção de dor, sintomas, avaliação física, capacidade para o trabalho e incapacidade.

RESULTADOS: Avaliações clínicas e afastamentos apresentaram correlações positivas com os aspectos subjetivos avaliados. O índice de capacidade para o trabalho apresentou correlação negativa com o índice de incapacidade física $(r=-0,69)$. Sintomas no momento da avaliação apresentaram boa correlação com resultados da escala de dor e achados clínicos. Afastamentos prévios mostraram associação com incapacidade (OR=1,13; IC 95\%:1,08;1,18).

CONCLUSÕES: Relato de sintomas e escala de dor podem ser úteis para avaliar condições presentes no momento da avaliação em indivíduos com distúrbios osteomusculares relacionados ao trabalho, pois são mais simples de aplicar. Em casos mais severos de lesões, avaliações clínicas e funcionais e questionários, tais como capacidade para o trabalho e incapacidade são preferíveis. Avaliações precisas e específicas desses distúrbios podem contribuir para decisões administrativas e legais mais justas.

\section{DESCRITORES: Saúde do trabalhador. Transtornos traumáticos cumulativos. Riscos ocupacionais. Avaliação da capacidade de trabalho.}

\section{INTRODUÇÃO}

Work-related musculoskeletal disorders (WRMDs) result in persistent pain, loss of functional capacity and work disability. These disorders have multifactorial genesis, including physical, organizational and individual factors and can correspond to different clinical diagnosis. Some of these are more specific, while others relate to diffuse signs and symptoms. ${ }^{\mathrm{a}}$

Their initial diagnosis is difficult because they are mainly based on complaints of pain and other symptoms. Conflicting social and economic interests may also be involved. ${ }^{11}$ Such difficulties leave open the possibility that relatively similar clinical conditions may have different diagnoses, thereby leading to distinct clinical, administrative and legal approaches. Therefore, further studies are needed in order to analyze the association between subjective descriptions and objective findings. ${ }^{2}$

Different procedures for measuring the perception of pain have been proposed. Among these, visual scales have been extensively utilized for measuring the se- verity of pain. Some of these have been considered to be simple, reliable and universally reproducible. ${ }^{9}$ However, pain is an essentially subjective experience that may be "associated with actual or potential tissue damage, or described in terms of such damage". ${ }^{12}$ The perceived dimensions may not represent the dimensions of a physical injury. Therefore, functional evaluations such as clinical evaluation and disability assessments have been considered useful for determining limitations. ${ }^{17}$ Pransky et $a l,{ }^{15}$ in a review of studies using questionnaires to assess general physical function, indicated that some of the self-reporting instruments reviewed showed good reliability and validity for detecting changes in illness status. Among the instruments extensively applied for evaluating disability is the Oswestry Low Back Pain Disability Questionnaire (ODQ). ${ }^{5}$ Although this was originally developed for measuring the level of functionality among patients with low back pain, it might be possible to apply it to other illnesses, in order to assess the impact of chronic pain on the daily activities of individuals. ${ }^{16}$ 
Another self-assessment instrument, the Work Ability Index (WAI) ${ }^{10}$ was originally proposed for evaluating how well a worker is able to perform the work, and to support aging workers in their changes over time. Applications of this instrument have shown good validity when compared to results from clinical examinations. ${ }^{4,19}$

Since the functional aspects of WRMDs seem to be influenced by the perception of pain, it would be useful to investigate the extent to which the functional factors - evaluated via ODQ (disability) and WAI (ability) - and objective factors (sick leave and clinical examination) correlate with other factors that are supposedly more subjective, such as the reporting of symptoms and the perception of pain. Therefore, the objective of the present study was to evaluate aspects of work-related musculoskeletal disorders among active workers at an industrial company.

\section{METHODS}

One hundred and thirty-four women took part in the study, which was carried out in São Carlos, Southeastern Brazil, in 2005. They were production-line workers in a large-sized multinational company ${ }^{\mathrm{a}}$ with approximately 2000 employees that produces office products. The participants were recruited from the sectors presenting the highest prevalence of sick leave, according to the company's medical data.

These workers performed tasks relating to: material preparation, i.e. sorting through non-manufactured material to separate out any defective pieces; assembling and finishing, i.e. feeding machines with raw material, sorting processed products and handling bundles of products; packaging products, i.e. feeding machines with processed and selected products. Some of these activities involved a static position of the neck and shoulders during precise repetitive movements of the wrists and fingers, including prehension movements and some extreme reaching to grasp distant objects, and a high pace of work. Some of the workplaces had been improved after an ergonomic intervention, while others were still being analyzed and waiting for changes. Individuals returning from sick leave were assigned to jobs presenting lower physical demands.

All the workers who had previously been on sick leave due to WRMDs were invited to participate. The additional inclusion criteria were that all participants had to be working at the time of data collection and that they did not present previous rheumatic diseases.
Seventy-three workers were identified and agreed to take part in the study. Their ages ranged from 22 to 53 years (mean=34.3; $\mathrm{SD}=7.0$ ). A similar number of agematched female workers presenting no previous sick leave, and from the same sectors, was invited to participate, and 61 workers agreed to take part in the study. Their ages ranged from 22 to 59 years (mean $=33.1$; $\mathrm{SD}=6.9$ ). The two groups together accounted for $72 \%$ of all the people working in those sectors.

After selection, these individuals were assessed by the following means:

1. Initial questionnaire: Personal information was obtained (age, marital status, and schooling) and the subjects' discomfort was characterized (feelings of heaviness, numbness, tingling or "pins and needles", pain, the onset and the duration of symptoms) according to the regions affected. These regions were divided into the neck, shoulders, elbow-forearm, and wrist-hand. Information relating to the length of work service and sick leave related to pain or musculoskeletal discomfort was obtained from the records available in the company.

2. Pain scale: The perceived present pain was assessed by means of a numerical pain scale from zero to ten, where zero represented total absence of pain and ten the greatest pain so far perceived. ${ }^{9}$

3. Physical examination: The protocol was based on the clinical literature and on the national legislation for evaluating WRMDs ${ }^{\mathrm{b}}$ that was in force at the time of data collection. Those regulations were subsequently replaced by the current regulations. ${ }^{\mathrm{c}}$ The examination consisted of careful inspection, palpation, evaluation of the amplitudes of functional movement, special detailed tests based on Hoppenfeld, ${ }^{8}$ such as the Adson, Filkenstein, and Phalen tests, and maneuvers to test bicipital and elbow tendonitis.

4. Oswestry Low Back Pain Disability Questionnaire (ODQ): This questionnaire is divided into sections designed to assess limitations on various activities of daily living such as personal care, lifting, walking, sitting and traveling. Each item can be graded from zero to five, with higher values representing greater disability. The total is expressed as a percentage value, which allows for classification of the subject's work ability into one of the following four categories: minimal disability, moderate disability, severe disability and total disability. It was originally developed for measuring disability

\footnotetext{
a Classification according to Instituto Brasileiro de Geografia e Estatística. Cadastro Central de Empresas, Diretoria de Pesquisas. Rio de Janeiro; 2000.

${ }^{b}$ Ministério da Previdência e Assistência Social. Ordem de Serviço nº 606 de, 05 de agosto de 1998. Aprova norma técnica sobre Distúrbios Osteomusculares Relacionados ao Trabalho- DORT. Diário Oficial da União. 5/8/98.

c Ministério da Previdência e Assistência Social. Instrução normativa n ${ }^{\circ} 98$ INSS/DC, de 05 de dezembro de 2003 . Aprova Norma Técnica sobre Lesões por Esforços Repetitivos-LER ou Distúrbios Osteomusculares Relacionados ao Trabalho-DORT. Diário Oficial da União. 5/12/03.
} 
among patients with low back pain and was adapted to assess the impact of WRMDs on functional abilities. Some questions relating to the daily activities performed by the upper limbs were added to the questionnaire, regarding levels of difficulty when washing clothes, hanging pieces on the clothesline, handling pans during cooking and handling shopping bags. The question related to traveling was excluded, as it was not a usual activity among the participants. This adaptation was done in such a way that it did not alter the general structure of the questionnaire. The applicability and consistency over time of this adapted version were evaluated in a pilot study involving other employees of the same company. The results from the pilot study indicated a high correlation between test and retest for the general value of the index, as well as for each individual question. Moreover, the ODQ presented high correlation $(\mathrm{r}=0.92)$ with the results from the physical examinations of these employees, thus indicating that the method allowed reliable inference of the functional and clinical characteristics evaluated.

5. Work Ability Index (WAI): This questionnaire ${ }^{18}$ included general and specific questions, and was used to evaluate the impact of WRMDs on the ability to work. Seven general questions related to age, sex, marital status, vocational/professional education, occupation, work task, workplace and department. The specific questionnaire covered seven items: current ability to work compared with lifetime best, ability to work in relation to the demands of the job, number of current diseases diagnosed by a physician, estimated work impairment due to diseases, sick leave during the past 12 months, own prognosis of ability to work two years from now, and mental resources. The answers to each question were scored. The final evaluation enabled classification of the subject's work ability into four categories: excellent, good, moderate and poor.

Data collection was performed during regular working hours, without any burden on the worker in the form of salary loss or additional hours. The questionnaires were administered to two participants at a time, who did not talk to each other, in a room within the company but outside of their normal work sector. The complete assessment was accomplished within approximately one hour. The sequence followed was the preliminary questionnaire first, followed by the pain scale, ODQ and finally WAI. The physical examination was performed afterwards, so that any pain elicited by the provocative tests would not interfere with the answers to the questionnaires or pain scale.
The physical examination was performed by two qualified physiotherapists who had received specific training. The inter-evaluator reliability in the physical examination had previously been verified by means of kappa $(\mathrm{k})$ statistics, which ranged from 0.78 to 0.86 , with a general mean of 0.81 . The clinical assessments were performed simultaneously by the two evaluators, although without exchange of the information obtained by each of them.

The results obtained from the pain scale were divided into categories according to the degree of severity of the pain, in a procedure that was similar to what was previously utilized by Björkstén et al. ${ }^{2}$ The responses to the scale were distributed into three categories, namely: slight, moderate and strong/intolerable.

The initial questionnaire for discomfort assessment enabled identification of 26 possible problems, considering all types of discomforts and bilateral body regions. However, a mean of 6.0 complaints $(\mathrm{SD}=$ 5.2) was identified. From the descriptive results, the median was used to classify the data into two groups as follows: no or minimal/moderate number of symptoms and high/excessive number of symptoms. Next, the median was applied again (upper and lower quartiles), thus enabling classification into four categories, as follows: no or minimal symptoms (0-1), moderate number of symptoms (2-4), high number of symptoms (5-8) and excessive number of symptoms ( 9 or more). This division was chosen, instead of just two categories (with and without symptoms), in order to better express the variability that was actually found.

A similar procedure was adopted for the clinical evaluations. The total number of positive findings, considering all tests and visual and tactile signs, was 112. However, the number of findings actually identified was lower (mean of $25.8, \mathrm{SD}=19$ ). From these numbers, the median was calculated and the results were classified into two groups as follows: no or minimal/moderate number of findings and high/excessive number of findings. Next, the median was applied again (upper and lower quartiles), thus enabling classification of the results into four categories, as follows: no or minimal findings (0-5), moderate findings (6-20), high number of findings (21$40)$ and excessive number of findings (41 or more).

The results were presented descriptively and correlated between each other, using Spearman's rank correlation coefficient for associations between categorical variables. The Chi-square test was utilized for associations that involved a nominal variable. Considering the large sample size, ${ }^{13}$ we applied regression to determine the nature of or average relationship between ordinal variables. ${ }^{1}$ The software utilized was Minitab 14.

a Walsh IAP, Coury HJCG, Alem MER, Turri J, Pinto P, Souza G, Rosa SMM. Repeatability of physical, functional and discomfort assessments in suffers from WRMDs. In: Proceedings of the Fifth International Scientific Conference on Prevention of Work-Related Musculoskeletal Disorders; 2004 July 11-15; Zurich, Switzerland. Zurich: Swiss Federal Institute of Technology; 2004. p. 599-600. 
The factors that presented correlations with the symptoms and the clinical findings using Spearman's rank correlation coefficient were then utilized in ordinal logistic regression analysis to evaluate the contribution of these factors towards the occurrence of these symptoms and the clinical findings. The factors that were associated with sick leave in the Chi-square test were utilized in multiple logistic regression analysis to evaluate the contributions of these factors towards associations with the occurrence of sick leave.

The study was approved by the local ethics committee. All participants were informed about its objectives, and those who agreed to participate signed a formal informed consent.

\section{RESULTS}

Table 1 shows the numbers and percentages of participants according to the personal, clinical and functional characteristics analyzed. The majority of the participants were less than 41 years old, had been working for six or more years, tended to report moderate or large numbers of symptoms of medium or high severity, and presented moderate to large numbers of clinical findings. With regard to functional characteristics, the participants tended to present minimal physical disability and good to moderate work ability. They were roughly evenly distributed between presenting no sick leave and having had at least one period of sick leave.

The results from the clinical examinations (Figure 1) and sick leave data (Figure 2), which are presumed to be the most objective indicators studied here, correlated positively with other variables. Significant and good correlations were found between clinical findings and symptoms $(\mathrm{r}=0.73)$, and between clinical findings and WAI ( $r=-0.69)$. Significant but moderate correlations were found between clinical findings and the pain scale $(r=0.56)$, and between clinical findings and ODQ $(\mathrm{r}=0.60)$. No significant association was identified between the results from clinical findings and sick leave (Figure 1). When comparing sick leave with the symptom reports and WAI, no significant association was identified, but a significant association was found between sick leave and the pain scale and ODQ ( $\mathrm{p} \leq 0.05$ ) (Figure 2). Finally, the two functional indicators (ODQ and WAI) were also compared to each other. A significant and good correlation between them was found $(\mathrm{r}=0.72, \mathrm{p} \leq 0.05)$.

The results from the ordinal logistic regression showed that the reported symptoms correlated with the results from the pain scale and clinical findings, but not with ODQ, WAI and sick leave. Clinical findings correlated with the reporting of symptoms and WAI results, but not with the pain scale and ODQ. Finally, sick leave was found to correlate well with ODQ, but only weakly with the pain scale (Table 2). In general, the odds ratio values were small, except for the association between individuals presenting lower number of clinical findings and higher work ability indexes.

Table 1. Personal, clinical and functional characteristics of all participants in the study. São Carlos, Southeastern Brazil, 2005.

\begin{tabular}{lcc}
\hline Variable & $\mathrm{N}$ & $\%$ \\
\hline Age (years) & & \\
$\quad \leq 30$ & 40 & 29.9 \\
$31-40$ & 75 & 56.0 \\
$\quad>41$ & 19 & 14.2 \\
Job tenure (years) & & \\
$<5$ & 34 & 25.4 \\
$6-10$ & 47 & 35.1 \\
$11-20$ & 43 & 32.1 \\
$>20$ & 10 & 7.5
\end{tabular}

Reporting of symptoms

$\begin{array}{lll}\text { No or minimal }(0-1) & 31 & 23.1 \\ \text { Moderate }(2-4) & 36 & 26.9 \\ \text { Large }(5-8) & 28 & 20.9 \\ \text { Excessive (9 or more) } & 39 & 29.1\end{array}$

Pain scale

$\begin{array}{lll}\text { No or minimal }(0-1) & 21 & 15.7 \\ \text { Moderate }(2-5) & 37 & 27.6 \\ \text { Large }(6-10) & 76 & 56.7\end{array}$

Clinical findings

No or minimal (0 - 5) $\quad 23 \quad 17.2$

Moderate $(6-20) \quad 42 \quad 31.3$

Large $(21-40) \quad 36 \quad 26.9$

Excessive (41 or more) $\quad 33 \quad 24.6$

Oswestry Disability Questionnaire

$\begin{array}{lll}\text { Minimal disability } & 64 & 47.8\end{array}$

$\begin{array}{lll}\text { Moderate disability } & 36 & 26.9\end{array}$

$\begin{array}{lll}\text { Severe disability } & 30 & 22.4\end{array}$

Total disability $\quad 4 \quad 3$

Work Ability Index

$\begin{array}{lll}\text { Excellent } & 26 & 19.4 \\ \text { Good } & 51 & 38.1 \\ \text { Moderate } & 41 & 30.6 \\ \text { Poor } & 16 & 11.9\end{array}$

Sick leave

\begin{tabular}{lll} 
No & 61 & 45.5 \\
Yes & 73 & 54.5 \\
\hline
\end{tabular}


Table 2. Regression parameters for symptom reports, clinical findings and sick leave. São Carlos, Southeastern Brazil, 2005.

\begin{tabular}{|c|c|c|c|c|}
\hline Variable & SE Coeff & OR & p & $95 \% \mathrm{Cl}$ \\
\hline \multicolumn{5}{|c|}{ Symptom reports (Ordinal logistic regression analysis) } \\
\hline Pain scale & 0.077 & 0.82 & 0.009 & $0.70 ; 0.95$ \\
\hline Clinical findings & 0.016 & 0.92 & 0.000 & $0.89 ; 0.95$ \\
\hline ODQ & 0.014 & 0.99 & 0.396 & $0.96 ; 1.02$ \\
\hline WAI & 0.290 & -0.99 & 0.972 & $-1.75 ; 0.56$ \\
\hline \multicolumn{5}{|c|}{ Clinical findings (Ordinal logistic regression analysis) } \\
\hline WAI & -0.298 & -2.61 & 0.001 & $-4.69 ;-1.46$ \\
\hline Symptom reports & 0.053 & 0.79 & 0.000 & $0.71 ; 0.88$ \\
\hline Pain scale & 0.078 & 0.93 & 0.379 & $0.80 ; 1.09$ \\
\hline ODQ & 0.015 & 0.98 & 0.102 & $0.95 ; 1.00$ \\
\hline \multicolumn{5}{|c|}{ Sick leave (Multiple logistic regression analysis) } \\
\hline ODQ & -0.023 & 1.13 & 0.000 & $1.08 ; 1.18$ \\
\hline Pain scale & 0.101 & 0.83 & 0.069 & $0.68 ; 1.01$ \\
\hline
\end{tabular}

WAI: Work Ability Index

ODQ: Oswestry Disability Questionnaire

SE Coeff: standard error coefficient

\section{DISCUSSION}

The results from the logistic regression analysis showed that the symptoms reported at the time of the assessment, which represent the most recent events, were well correlated with the results from the pain scale and clinical findings, because these also evaluated aspects of the present condition. Likewise, the clinical findings and symptom reports were also well correlated in relation to each other. On the other hand, previous sick leave, which represented a more remote event, correlated with the results from the disability assessment (ODQ), which also represented older and more severe injuries.

The results from the pain scale correlated with the results from the symptom reports. Both instruments were strongly based on the subjects' perceptions and, therefore provided validation for individuals' responses regarding their assessments of their present clinical condition.

Clinical findings and symptom reports are instruments of differing nature, considering that the clinical examination is performed by the evaluator by means of provocative tests, while the reporting of symptoms is the result of the individual's perception. Nonetheless, they were well correlated, probably because the two instruments assessed the same dimension of the problem, i.e. the clinical condition and the resultant symptoms that were presented by the individual at the time of the assessment.

The relationships between the reporting of symptoms, pain scale and clinical findings indicated that the subject's current state was well recognized by the instruments utilized for this purpose. Thus, it can be suggested that the use of symptom reports that also involve assessments of pain symptoms would be preferable to clinical evaluations for assessing current conditions among individuals presenting WRMDs, as they are easier to apply and require less professional attention and training. This would be particularly valid when more recent stages of such disorders are evaluated.

The clinical findings correlated with the results from the Work Ability index. Subjects presenting higher numbers of clinical findings were 2.6 times as likely to present lower ability to work. This index, just like the clinical findings, also reflects the individual's current state, considering that it measures the ability to work and that all the subjects were active at the time that the present study was conducted.

Studies by Eskelinen et a ${ }^{4}$ and Nygard at a ${ }^{14}$ observed a satisfactory relationship between the functional and subjective results from WAI and the results from more objective measurements. Eskelinen et $\mathrm{al}^{4}$ compared the clinical assessments of health status and work ability with the subjective assessments, as reported on a questionnaire, and found a good correlation between them. Nygard et $\mathrm{al}^{14}$ also studied the relationship between objectively measured physical and mental functional capacity and work, and found that objective physical measurements such as muscle strength correlated with WAI. In the present study the negative relationship between clinical findings and WAI was the strongest association found between the results analyzed. The clinical findings involved the presence of physical signs, thus indicating that the more advanced stages of the disorders had been reached. Therefore, it would in some manner be expected that these changes could interfere in the workers' physical capacities. 


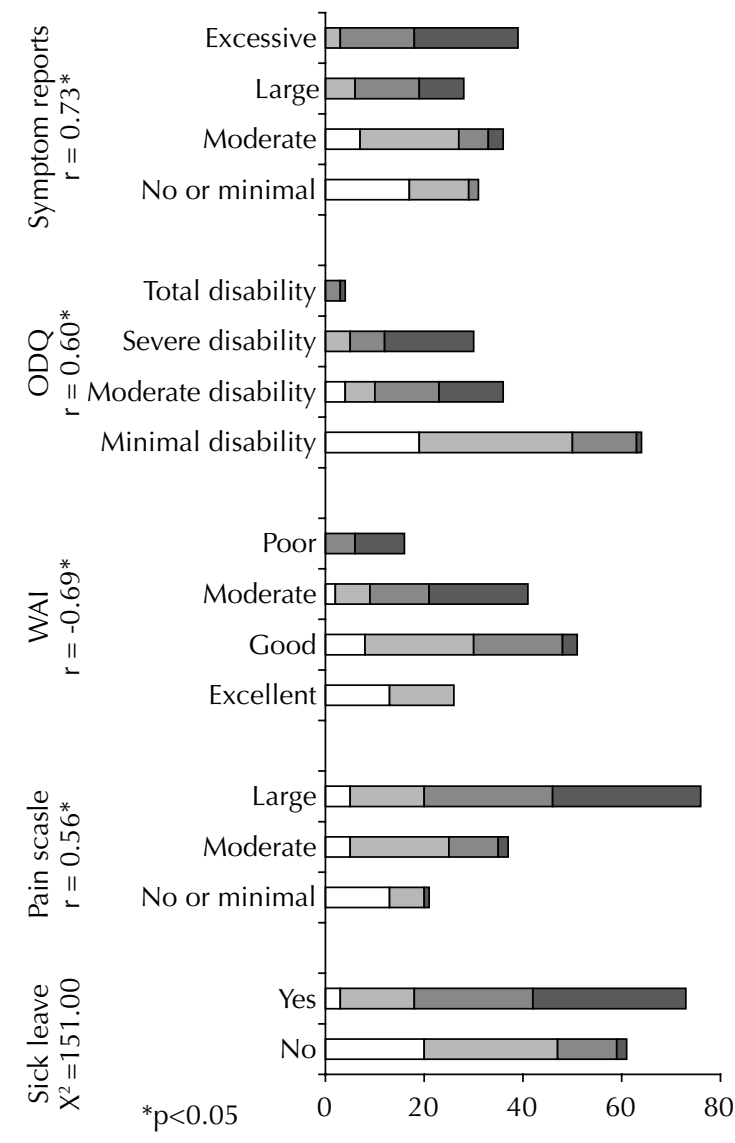

$\square \mathrm{No} /$ Minimal clinical findings

$\square$ Moderate clinical findings

- Large clinical findings

$\square$ Excessive clinical findings

Figure 1. Relation between clinical findings and other variables. São Carlos, Southeastern Brazil, 2005.

Previous sick leave, which is usually analyzed when more serious consequences of injuries are present, did not correlate with any events other than the incapacity measured by ODQ. This evaluates functional losses that are more severe and that not only are reflected in the work activities considered by WAI, but also in activities of daily living. Loisel et a $\mathrm{l}^{10}$ utilized an optical-electrical device for measuring trunk kinematics and ODQ when studying the relationship between the results from these instruments and work status. In that study, the ODQ score correlated significantly with work status, whereas spinoscope scores were not. Likewise, Grönblad et $\mathrm{al}^{7}$ showed that patients who had taken sick leave had significantly higher ODQ scores, and that disability measurements were clearly influenced by patients' work status.

The absence of any association between the results from current clinical findings and sick leave needs to be

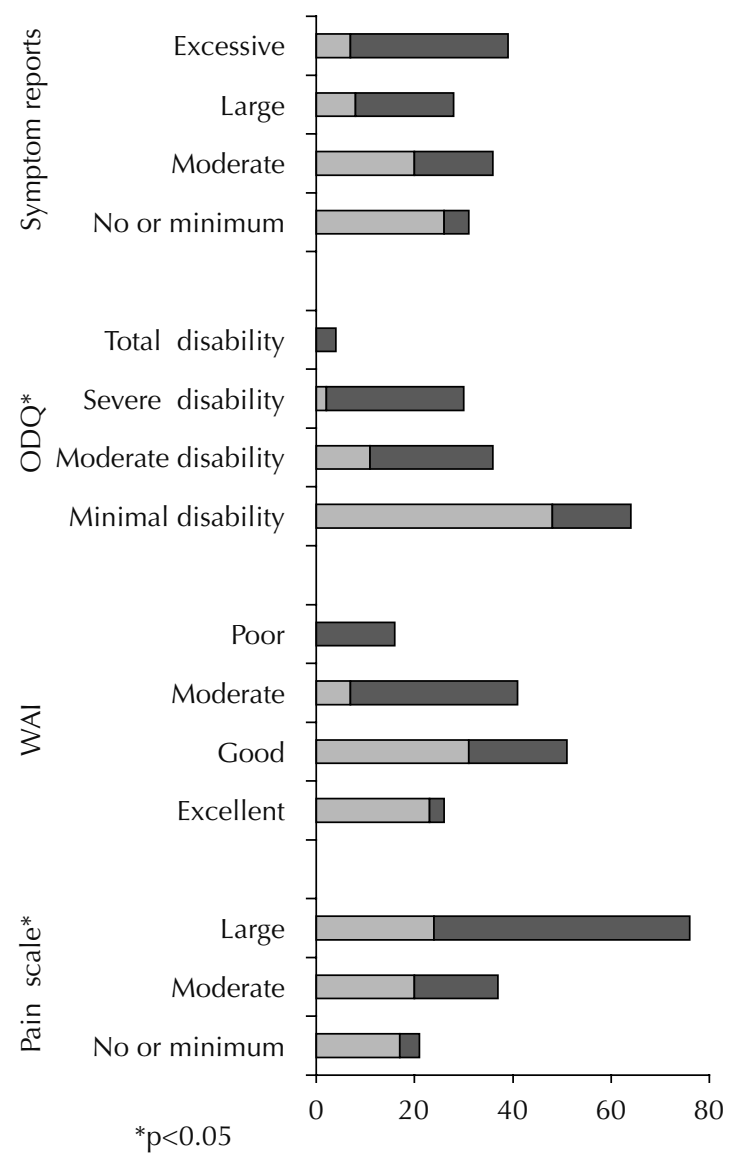

$\square$ No sick leave

$\square$ Sick leave

Figure 2. Relation between sick leave and other variables. São Carlos, Southeastern Brazil, 2005.

considered in the light of the participants' work history. Approximately $75 \%$ of the participants had been working for six years or more at the time of the study. Most of the workers who had been on sick leave were older and had worked in less modern workplaces, i.e. before any ergonomic intervention had taken place. Although all the workers were undergoing some form of job rotation schedule, the workers who had been on sick leave were particularly assigned to jobs presenting lower physical demands, while healthy workers were assigned to jobs still waiting for changes. Thus, the prevalence of symptoms and disorders in these jobs was high, and the absence of association between previous sick leaves and current symptoms was not unexpected.

Some discrepancies between subjects reporting symptoms and the presence of clinical findings were also observed. Some subjects who did not report any symptoms presented clinical findings in the assessment. A small number of subjects reported a moderate number 
of symptoms but did not have any clinical findings from the physical evaluation. Björkstén et $\mathrm{al}^{2}$ studied women who were doing monotonous and repetitive precision work, and found that some objective findings differed from the subjective symptoms. Nevertheless, consistent values were found for most of the subjects, thereby indicating the validity of the subjective reports.

Although some studies have used different self-reporting instruments for evaluating disability and ability, and for investigating their reliability over time, ${ }^{3,6}$ studies analyzing the association between these factors are rare in the available literature. In the present study, the results from the ODQ and WAI showed good correlation between each other. However, when disability and ability factors were compared with other variables, the WAI scores were shown to be more sensitive for explaining current functional states (clinical findings), whereas the ODQ scores were more sensitive for explaining more remote and severe outcomes (sick leave).
Finally, the results from the present study indicate that, for active workers, the current state of WRMDs is better assessed by instruments that are capable of representing the characteristics at the actual time of the assessment. Symptom reports may be preferable to clinical evaluations for assessing current conditions among individuals presenting more recent WRMDs, as they are easier to apply and require less professional attention and training. In more severe cases of such disorders, clinical evaluations and questionnaires for assessing more functional characteristics, such as those relating to the ability to work and disability, are preferable. The use of previous sick leave as a means of identifying occupational risks may be an inefficient strategy for preventing current disorders from worsening when the subjects have moved from the original job to others. In addition, more precise evaluations of these disorders may contribute towards more adequate characterization of such injuries, which in turn may contribute towards fairer legal and administrative decisions. 


\section{REFERENCES}

1. Agrest A. Categorical data analysis. 2.ed. New York: John Wiley; 2002.

2. Björkstén MG, Boquist B, Talbäck $M$, Edling $C$. The validity of reported musculoskeletal problems. A study of questionnaire answers in relation to diagnosed disorder and perception of pain. App/ Ergon. 1999;30(4):325-30.

3. Davidson M, Keating JL. A comparison of five Low Back Pain Disability Questionnaires: reliability and responsiveness. Phys Ther. 2002;82(1):8-24.

4. Eskelinen L, Kohvakka A, Merisalo T, Hurri H, Wägar G. Relationship between the self-assessment and clinical assessment of health status and work ability. Scand J Work Environ Health. 1991;17(Supl 1):40-7.

5. Fairbank JC, Couper J, Davies JB, O'Brien JP. The Oswestry low back pain disability questionnaire. Physiotherapy. 1980;66(8):271-3.

6. Fritz JM, Irrgang JJ. A comparison of a modified Oswestry Low Back Pain Disability Questionnaire and the Quebec Back Pain Disability Scale. Phys Ther. 2001;81(2):776-88.

7. Grönblad M, Järvinen E, Hurri H, Hupli M, Karaharju EO. Relationship of the Pain Disability Index (PDI) and the Oswestry Disability Questionnaire (ODQ) with three dynamic physical tests in a group of patients with chronic low-back and leg pain. Clin J Pain. 1994;10(3):197-203

8. Hoppenfeld S. Physical examination of the spine and extremities. New York: Appleton-Century-Crofts; 1983.

9. Huskisson E. Visual Analogue Scales. In: Melzack R, editor. Pain Measurement and Assessment. New York : Raven Press; 1983. p.33-7.

10. Loisel $P$, Poitras $S$, Lemaire J, Durand $P$, Southière $A$, Abenhaim L. Is work status of low back pain patients best described by an automated device or by a questionnaire? Spine. 1998;23(14):1588-95.
11. Martin B, Bammer G. When Experts Disagree. In: Ranney D, editor. Chronic musculoskeletal injuries in the workplace. Philadelphia: WB Saunders Company; 1997. p.101-13.

12. Merskey H, Albe-Fessard DG, Bonica JJ, Carmon A, Dubner R, Kerr FWL, Lindblon U, Pagni CA, Renaer MJ, Sternback RA, Sunderland S. Pain terms: a list with definitions and notes on usage. Recommended by IASP Subcommittee of Taxonomy. Pain. 1979;6(3):249-52.

13. Mood AM, Graybill FA, Boes DC. Introduction to the Theory of Statistics. Tókio: McGraw-Hill- Koga Kusha; 1997.

14. Nygard CH, Eskelinen L, Suvanto S, Tuomi K, Ilmarien J. Associations between functional capacity and work ability among elderly municipal employees. Scand J Work Environ Health. 1991;17(Supl 1):122-7.

15. Pransky G, Feuerstein M, Himmelstein J, Katz JN, Vickers-Lahti M. Measuring functional outcomes in work-related upper extremity disorders. Development and validation of the Upper Extremity Function Scale. J Occup Envir Med. 1997;39(12):1195-202.

16. Ranney D. Disability Assessment Forms. In: Ranney D, editor. Chronic musculoskeletal injuries in the workplace. Philadelphia: WB Saunders Company; 1997. p.314-8.

17. Rossignol M. Establishing a Prognosis for Low Back Problems. In: Ranney D, editor. Chronic musculoskeletal injuries in the work place. Philadelphia: WB Saunders Company; 1997. p.193215.

18. Tuomi K, Ilmarinen J, Jahkola A, Katajarinne L, Tulkki A. Índice de Capacidade para o Trabalho. Trad. De FM Fischer. São Carlos: EDUFSCar; 2005.

19. Zwart BC, Frings-Dressen MH, van Duivenbooden JC. Test-retest reliability of the Work Ability Index questionnaire. Occup Med (Lond). 2002;52(4):177-81.

Funded by Conselho Nacional de Desenvolvimento Científico e Tecnológico (CNPQ - Process N. 550487/2002-6). 